\title{
The decrease of IGF-I, IGF-binding protein-3 and bone alkaline phosphatase isoforms during gluten challenge correlates with small intestinal inflammation in children with coeliac disease
}

\author{
Ulf H G Jansson ${ }^{1,2}$, Bengt Kristiansson ${ }^{1}$, Per Magnusson ${ }^{3,4}$, Lasse Larsson ${ }^{3}$, Kerstin Albertsson-Wikland ${ }^{1}$ \\ and Ragnar Bjarnason ${ }^{1}$ \\ ${ }^{1}$ Göteborg Paediatric Growth Research Centre, Department of Paediatrics, University of Göteborg, Göteborg, Sweden, ${ }^{2}$ Department of Paediatrics, \\ Ryhov County Hospital, Jönköping, Sweden, ${ }^{3}$ Bone and Mineral Metabolic Unit, Division of Clinical Chemistry, Department of Biomedicine and Surgery, \\ Linköping University Hospital, Linköping, Sweden and ${ }^{4}$ Research Service (151), Musculoskeletal Disease Center, Jerry L Pettis Memorial VA Medical \\ Center, Loma Linda, California, USA \\ (Correspondence should be addressed to U Jansson, Göteborg Paediatric Growth Research Centre, Department of Paediatrics, University of Göteborg, The \\ Queen Silvia Children's Hospital, SU/Östra, S-41685, Göteborg, Sweden; fax: +46-36-322234)
}

\begin{abstract}
Objective: In children with coeliac disease, the ingestion of gluten causes small intestinal inflammation and a clinical picture of malabsorption, weight reduction and short stature. Decreased alkaline phosphatase (ALP) during gluten challenge was found in a previous study. ALP is a marker of bone formation and ALP activities are correlated with growth velocity. The aim of this study was to characterise the previously observed decrease of total ALP by investigating three specific bone ALP isoforms (bone/intestinal, B1 and B2) and three specific liver ALP isoforms (L1, L2 and L3) and, moreover, to correlate these ALP isoforms with other growth factors and growth markers. In addition, we also studied the association with possible weight changes, small intestinal mucosa inflammation, sex, age and gluten dose during gluten challenge.

Materials and methods: Bone and liver ALP isoforms, IGF-I, IGF-binding protein (IGFBP)-3 and serum cross-linked carboxy-terminal telopeptide of type I collagen (ICTP) were measured together with change in weight and small intestinal mucosa histopathology in 54 children with earlier enteropathy who participated in a 4-week gluten challenge.

Results: We observed a decreased total ALP activity after 4 weeks of gluten challenge, $7.8 \pm 1.8$ to $6.5 \pm 1.7 \mu \mathrm{kat} / \mathrm{l}$ (means \pm s.D.), which was mainly due to a reduction of the bone ALP isoforms. The sum of all three bone ALP isoforms decreased from $6.3 \pm 1.7$ to $5.1 \pm 1.6 \mu \mathrm{kat} / \mathrm{l}$. The decreased activities of the bone ALP isoforms correlated with the observed reductions of IGF-I $(r=0.74$, $P<0.001)$, IGFBP-3 $(r=0.51, P<0.001)$ and ICTP $(r=0.57, P<0.001)$. The decrease of the growth factors and growth markers correlated with weight reduction, but when influences from the change in weight were adjusted for, the partial correlation of the small intestinal mucosa inflammation was significant for IGF-I $(r=-0.56, P<0.001)$ and IGFBP-3 $(r=-0.55, P<0.001)$.

Conclusion: The decrease of total ALP was due to a reduction of bone ALP. The decrease of IGF-I and IGFBP-3 was independently correlated with weight change and small intestinal inflammation.
\end{abstract}

European Journal of Endocrinology $144417-423$

\section{Introduction}

In coeliac disease, a prevalent chronic disease in childhood, ingestion of gluten causes an inflammation in the small intestinal mucosa. Gastrointestinal symptoms are common, and poor weight gain or weight loss is often the main manifestation, at least in younger children (1); in addition, linear growth may also be hampered (2). The presenting symptoms are related to the amount of gluten consumed and the age of the patient (1).

Stunting, i.e. decreased growth velocity leading to short stature, has often been considered a consequence of gluten-induced chronic malnutrition starting with weight reduction. However, stunting has been reported to be the sole manifestation of coeliac disease (3). Mechanisms other than malabsorption have to be considered to explain such a manifestation of the disease.

In a previous study of gluten challenge in children with coeliac disease, we observed a decreased total alkaline phosphatase (ALP) activity (4). Total ALP activity in serum is mainly of skeletal origin in children and adolescents, and bone ALP is considered to be a marker of growth as well as a marker of bone 
formation. Bone ALP activity is particularly high during the pubertal growth spurt. In this study we have used a previously described weak anion-exchange HPLC method which can resolve six different ALP isoforms in serum from healthy individuals: bone/ intestinal (B/I), a minor fraction composed of bone and intestinal ALP; two major bone ALP isoforms (B1 and B2); and three liver ALP isoforms (L1, L2 and L3) (5, 6). The major bone ALP isoforms, B1 and B2, differ due to variations in glycosylation patterns (7). Decreased levels of insulin-like growth factor (IGF)-I and IGFbinding protein (IGFBP)-3 have been reported in previous studies of coeliac disease $(8,9)$. An altered growth hormone (GH)/IGF-I axis may be induced by malnutrition and can theoretically also be the result of direct interference of the GH-signalling pathway or of impaired liver function with low synthesis of IGF-I. Several studies have shown the liver to be involved in coeliac disease, with increase of serum levels of alanine and aspartate aminotransferases (ALAT and ASAT), even in the absence of malabsorption $(10,11)$.

Growth impairment and short stature are common manifestations of intestinal inflammatory disorders such as Crohn's disease (12), as well as of other inflammatory conditions such as juvenile chronic arthritis (13). Inflammation also leads to decreased bone mineral density (BMD), another reported consequence of coeliac disease (14). Whether the reduction of IGF-I and IGFBP-3 in the studies of coeliac disease mentioned above $(8,9)$ was a consequence of the inflammation or secondary to the malabsorption with weight loss was not established (15). IGF-I and IGFBP-3 are considered as growth factors closely involved in and partly controlling growth plate activity. Serum ALP is considered to be a marker of growth activity, on a secondary level, reflecting growth rate but not influencing it. All three may therefore be suited to assess short-term variations in growth.

The aims of this study were to further investigate the significance of the decrease of ALP during gluten challenge in children with coeliac disease and to characterise the decrease by specific ALP isoforms and explore associated changes in other growth factors and markers and the relationship with weight gain, inflammatory response in the small intestine, sex, age and gluten dose.

\section{Patients and methods}

The study cohort comprised 57 children with verified enteropathy who had been on a gluten-free diet for at least 12 months. The 54 children (33 girls and 21 boys) who completed the study had a mean age at challenge of $32 \pm 12.3$ months (mean \pm s.D.) and a median of 30 months (range 2.0-9.3 years). At the start of the challenge, the average weight was $0.35 \pm 1.1$ standard deviation scores (SDS) and height was $-0.02 \pm 1.0$ SDS. This cohort consisted of consecutive cases during 1 year at the paediatric departments of the County Hospital of Jönköping and Queen Silvia Children's Hospital of Göteborg, both situated in south-western Sweden. Gluten challenge was performed as part of the routine clinical investigation of suspected coeliac disease according to ESPGHAN (European Society of Paediatric Gastroenterology, Hepatology and Nutrition) criteria (16). Three patients were excluded from the study. Two of them were excluded due to failure of compliance. They had severe early symptoms and discontinued gluten consumption within the first week without an immediate small intestinal biopsy. One patient was excluded as she had been considered after the initial 4 weeks to show relapse, which at the final evaluation could not be confirmed. Of the 54 patients, 51 had biopsy-proven mucosal relapse of coeliac disease within 4 weeks, and three patients needed a total of 8 weeks before relapse.

During challenge the mean enteropathy score (ES, see below for scoring method) increased from $4.6 \pm 0.8$ to $12.4 \pm 2.9$. The mean change $(\Delta)$ of weight was $-0.21 \pm 0.25$ SDS. The median weight reduction was $110 \mathrm{~g}$, compared with an expected weight increase of approximately $250 \mathrm{~g}$. To compensate for this, and weight variations due to age and sex, all weights were transformed to SDS (17).

\section{Study protocol}

The gluten challenge started after confirmation of a normal or near-normal mucosa on small intestinal biopsy. The children were randomised to either 0.2 or $0.5 \mathrm{~g}$ gluten $/ \mathrm{kg}$ body weight per day, added to their otherwise gluten-free diet. The challenge was planned for 4 weeks. To facilitate compliance, a paediatric dietician provided a list of commodities and recipes. The protocol included daily registration of the exact gluten intake and weekly interviews with registration of symptoms. Blood was sampled at the start and after 4 weeks. Weight was measured at the same time of day, preceded by $4 \mathrm{~h}$ of fasting and transformed to SDS calculated from a reference population.

The small intestinal biopsy was repeated after 4 weeks. Those who had not relapsed by then continued for another 4 weeks with a gluten dose of $0.5 \mathrm{~g} / \mathrm{kg}$ per day. The second 4 week challenge period was followed by a third small intestinal biopsy.

\section{Mucosal evaluation}

A preliminary evaluation was done immediately after the biopsy. Upon completion of the study, an experienced pathologist evaluated the mucosal specimens serially and on the same occasion. In the histopathological evaluation, four morphological characteristics of small intestinal mucosa inflammation were scored quantitatively or semiquantitatively on a scale of 1 to 4, namely: villous-to-crypt ratio, number of 
intra-epithelial lymphocytes, degree of surface epithelium damage and degree of inflammatory infiltrate in the mucosa. The sum of these four scores has been termed the ES in this study. An ES of 4 represents a normal mucosa and 16 a maximum level of intestinal changes.

\section{Biochemical determinations}

IGF-I Serum concentrations of IGF-I were measured by an IGFBP-blocked RIA without extraction and in the presence of an approximately 250-fold excess of IGF-II (Mediagnost $\mathrm{GmbH}$, Tübingen, Germany). The intraassay coefficient of variation (CV) values were 8.1, 4.4 and $4.5 \%$ at concentrations of 55,219 and $479 \mu \mathrm{g} / \mathrm{l}$ respectively (18).

IGFBP-3 The serum IGFBP-3 was determined by a previously reported RIA (18). The intra-assay CV values were $6.2,5.6$ and $4.6 \%$ at concentrations of 1964, 2927 and $4799 \mu \mathrm{g} / \mathrm{l}$ respectively.

As serum concentrations of IGF-I and IGFBP-3 are age-dependent, the values were converted into SDS using prepubertal reference values from our centre (19).

Serum ALP isoforms The bone ALP and liver ALP isoforms were determined by a previously described HPLC method $(5,6)$. A weak anion-exchange column, SynChropak AP300 (250 mm×4.6 mm internal diameter) (MICRA Scientific Inc., Northbrook, IL, USA), was used instead of the originally described SynChropak AX300, optimised for bone ALP isoform analysis (7). Total ALP activity was measured with a routine method (20). The relationship between the enzyme activity units kat and $U$ is $1 / 60$, i.e. $1.0 \mu \mathrm{kat} / \mathrm{l}$ corresponds to $60 \mathrm{U} / \mathrm{l}$.

Serum cross-linked carboxy-terminal telopeptide of type I collagen (ICTP) Serum ICTP was determined by means of a commercially available RIA kit (Orion Diagnostica, Oulunsalo, Finland). The intra-assay CV values were 6.2 and $2.8 \%$ at 3.8 and $40.5 \mu \mathrm{g} / \mathrm{l}$ respectively $(21)$.

Serum concentrations of ALAT and ASAT recorded at the start and the end of the gluten challenge of this same cohort and used in another study (4) were used for calculation of correlations. The significant increase of ALAT was from 0.32 to $0.51 \mu \mathrm{kat} / \mathrm{l}$ and of ASAT from 0.57 to $0.70 \mu \mathrm{kat} / \mathrm{l}$. ALAT remained within the reference values except for 6 out of 54 patients.

\section{Definitions}

The term 'growth factors' is used for IGF-I and IGFBP-3 and the term 'growth markers' for total ALP, bone ALP and ICTP. Bone ALP is the sum of the isoforms $\mathrm{B} / \mathrm{I}, \mathrm{B} 1$ and $\mathrm{B} 2$ and liver ALP is the sum of the isoforms L1, L2 and L3.
Table 1 Change in total ALP and bone and liver ALP isoforms, IGF-I, IGFBP-3 and ICTP during 4 weeks of gluten challenge (means \pm S.D.). The values of the various ALP isoforms are in $\mu \mathrm{kat} / \mathrm{l}$ otherwise $\mu \mathrm{g} / \mathrm{l}$. Bone ALP is the sum of $\mathrm{B} / \mathrm{l}, \mathrm{B} 1$ and $\mathrm{B} 2$ and liver ALP is the sum of $L 1, L 2$ and $L 3$ isoforms.

\begin{tabular}{lrrrc}
\hline & \multicolumn{1}{c}{ Start } & Four weeks & $\begin{array}{c}\text { Mean } \\
\text { difference }\end{array}$ & $\boldsymbol{P}$ \\
\hline Total ALP & $7.77 \pm 1.82$ & $6.48 \pm 1.67$ & $-1.28 \pm 1.40$ & $<0.001$ \\
Bone ALP & $6.30 \pm 1.74$ & $5.08 \pm 1.56$ & $-1.25 \pm 1.27$ & $<0.001$ \\
B/I ALP & $0.27 \pm 0.12$ & $0.23 \pm 0.10$ & $-0.04 \pm 0.08$ & $<0.001$ \\
B1 ALP & $1.47 \pm 0.46$ & $1.20 \pm 0.37$ & $-0.27 \pm 0.32$ & $<0.001$ \\
B2 ALP & $4.55 \pm 1.27$ & $3.64 \pm 1.18$ & $-0.94 \pm 0.98$ & $<0.001$ \\
Liver ALP & $1.47 \pm 0.38$ & $1.40 \pm 0.42$ & $-0.06 \pm 0.39$ & 0.18 \\
L1 ALP & $0.61 \pm 0.32$ & $0.65 \pm 0.36$ & $0.05 \pm 0.35$ & 0.29 \\
L2 ALP & $0.64 \pm 0.16$ & $0.55 \pm 0.14$ & $-0.08 \pm 0.16$ & $<0.001$ \\
L3 ALP & $0.22 \pm 0.06$ & $0.20 \pm 0.06$ & $-0.02 \pm 0.06$ & $<0.05$ \\
IGF-I SDS & $-0.06 \pm 1.00$ & $-1.23 \pm 1.20$ & $-1.17 \pm 1.07$ & $<0.001$ \\
IGFBP-3 & $-0.30 \pm 0.93$ & $-1.01 \pm 0.93$ & $-0.71 \pm 0.68$ & $<0.001$ \\
$\quad$ SDS & & & & \\
ICTP & $14.54 \pm 2.67$ & $11.35 \pm 3.04$ & $-3.19 \pm 2.98$ & $<0.001$
\end{tabular}

$\Delta$ as a prefix of a test indicates the difference of two values over time, i.e. between the start and end of the gluten challenge.

\section{Statistics}

The results are presented as mean with the standard deviation (S.D.) in parenthesis. Changes between the start and the end of the challenge were compared with Wilcoxon's matched pairs test. For examining correlations, Spearman's rank order correlation $\left(r_{\mathrm{S}}\right)$ was used. Differences between groups were analysed with the Mann-Whitney $U$ test. Multiple regression analysis was used to determine combined effects of several variables. Adjustments for confounding variables in correlation analyses were done by using Spearman partial correlation coefficient. All statistical tests

Table 2 Influence of $\Delta$ weight and $\Delta \mathrm{ES}$ upon change of growth markers and growth factors. $\Delta$ Weight showed significant correlation with all growth factors and markers. The result was the same for change of mucosal inflammation except for $\triangle I C T P$.

\begin{tabular}{|c|c|c|c|c|}
\hline & \multicolumn{2}{|c|}{$\begin{array}{c}\text { Spearman rank } \\
\text { correlation } \\
\text { for } \Delta \text { weight SDS }\end{array}$} & \multicolumn{2}{|c|}{$\begin{array}{l}\text { Spearman rank } \\
\text { correlation } \\
\text { for } \Delta E S\end{array}$} \\
\hline & $r_{\mathrm{s}}$ & $P$ & $r_{\mathrm{s}}$ & $P$ \\
\hline$\Delta$ Total ALP $(\mu \mathrm{kat} / \mathrm{l})$ & 0.58 & $<0.001$ & -0.38 & $<0.01$ \\
\hline$\Delta$ Bone ALP $(\mu \mathrm{kat} / \mathrm{l})$ & 0.56 & $<0.001$ & -0.35 & $<0.05$ \\
\hline$\Delta \mathrm{B} / \mathrm{l}$ bone $\mathrm{ALP}(\mu \mathrm{kat} / \mathrm{l})$ & 0.31 & $<0.05$ & -0.33 & $<0.05$ \\
\hline$\Delta \mathrm{B} 1$ bone ALP $(\mu \mathrm{kat} / \mathrm{l})$ & 0.39 & $<0.01$ & -0.40 & $<0.01$ \\
\hline$\Delta \mathrm{B} 2$ bone ALP $(\mu \mathrm{kat} / \mathrm{l})$ & 0.56 & $<0.001$ & -0.32 & $<0.05$ \\
\hline$\Delta \mathrm{IGF}-\mathrm{I}$ SDS & 0.59 & $<0.001$ & -0.52 & $<0.001$ \\
\hline$\Delta$ IGFBP-3 SDS & 0.40 & $<0.01$ & -0.50 & $<0.001$ \\
\hline$\Delta \mathrm{ICTP}(\mu \mathrm{g} / \mathrm{l})$ & 0.46 & $<0.001$ & -0.25 & $<0.07$ \\
\hline
\end{tabular}


were two-sided with a minimum level of 0.05 for significance.

\section{Ethics}

The study was approved by the ethics committees of the medical faculties of the Universities of Göteborg and Linköping. Informed consent was obtained from the parents.

\section{Results}

\section{$\triangle A L P, \triangle$ bone ALP and $\triangle$ liver ALP}

Serum concentrations of total ALP, bone ALP, the three bone ALP isoforms B/I, B1 and B2 and liver isoforms L2 and L3 decreased significantly during gluten challenge, whereas liver ALP and L1 were unchanged (Table 1). The percentage of bone ALP and liver ALP at the start and at the end of the challenge was the same, 81 and $19 \%$ at the start, and 78 and $22 \%$ at the end $(P=0.70)$.

\section{$\triangle I G F-I, \triangle I G F B P-3$ and $\triangle I C T P$}

Serum concentrations of IGF-I, IGFBP-3 and ICTP decreased significantly during gluten challenge (Table 1).

\section{ALP and correlation with IGF-I, IGFBP-3 and ICTP}

There was a correlation between $\triangle$ ALP and $\triangle$ IGF-I $\left(r_{\mathrm{S}}=0.77, P<0.001\right), \Delta$ IGFBP-3 $\left(r_{\mathrm{S}}=0.52, P<0.001\right)$ and $\Delta$ ICTP $\left(r_{\mathrm{S}}=0.61, \quad P<0.001\right) . \quad \Delta$ Bone ALP correlated with $\Delta$ IGF-I $\quad(r=0.74, \quad P<0.001)$, $\Delta$ IGFBP-3 $(r=0.51, P<0.001)$ and $\Delta$ ICTP $(r=$ $0.57, P<0.001)$. The $\Delta$ bone ALP isoforms $\mathrm{B} / \mathrm{I}, \mathrm{B} 1$ and $\mathrm{B} 2$ was correlated with $\Delta$ IGF-I, $\Delta$ IGFBP-3 and $\Delta \mathrm{ICTP}$.

\section{IGF-I and IGFBP-3 and liver enzymes}

There was no statistical correlation between $\triangle$ IGF-I SDS and $\triangle$ ASAT $\left(r_{\mathrm{S}}=-0.26, P=0.06\right)$ or $\triangle$ ALAT $\left(r_{\mathrm{S}}=-0.25, P=0.07\right)$, or for $\Delta \mathrm{IGFBP}-3$ SDS and $\triangle$ ASAT $\left(r_{\mathrm{S}}=-0.27, P=0.055\right)$ and for $\triangle$ ALAT $\left(r_{\mathrm{S}}=-0.20, P=0.14\right)$.

\section{Growth factors, growth markers and their relationship with change in weight and enteropathy}

There was a significant correlation between weight loss and ES and the growth factors and all growth markers except ICTP (Table 2). There was no difference in $\Delta$ growth factors or $\Delta$ growth markers with respect to
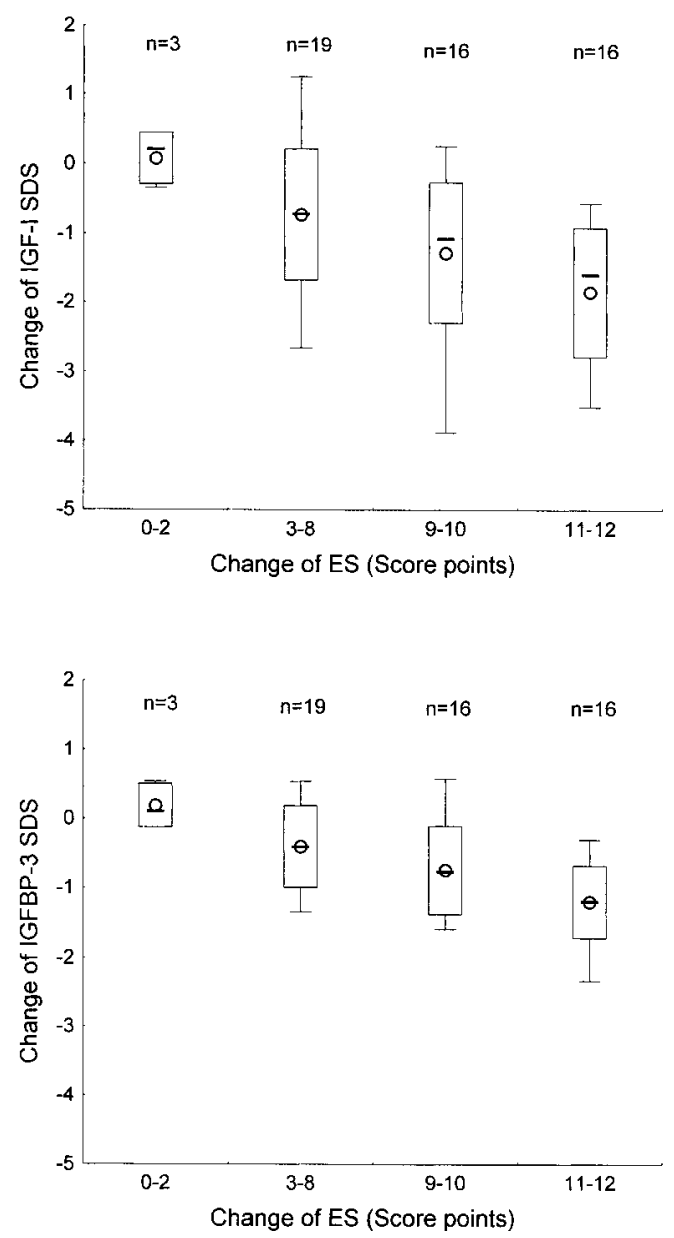

Figure $1 \Delta$ ES was correlated with $\Delta$ IGF-I SDS $\left(r_{\mathrm{S}}=-0.52, P<\right.$ $0.001)$ and with $\Delta$ IGFBP-3 SDS $\left(r_{S}=-0.50, P<0.001\right)$. This is illustrated in the diagram where groups with increasing $\Delta E S$ correspond to decreased values of $\Delta$ IGF-I SDS and $\Delta$ IGFBP-3 SDS. Whiskers, max/min; circle and box, mean \pm s.D.; horizontal line, median.

age, gluten dose or sex (data not shown). The $\Delta \mathrm{IGF}-\mathrm{I}$ and $\triangle$ IGFBP-3 within four groups with various degrees of $\Delta \mathrm{ES}$ are shown in Fig. 1.

\section{Combined influences on growth factors and growth markers}

The combined contribution of $\Delta$ weight SDS, $\Delta \mathrm{ES}$, age at challenge, gluten amount and sex to the $\Delta$ growth factors and $\Delta$ growth markers during gluten challenge was evaluated in multiple regression (Table 3). When combined, in multiple regression, $\Delta$ weight SDS was significantly correlated with the $\triangle$ ALP, $\Delta$ bone ALP and $\Delta \mathrm{ICTP}$ while $\Delta \mathrm{ES}$, age, sex and dose of gluten were not. Both $\Delta$ weight SDS and $\Delta \mathrm{ES}$ were significantly correlated with the $\Delta$ IGF-I and $\triangle$ IGFBP-3. Of the ALP isoforms, $\Delta \mathrm{B} 1, \Delta \mathrm{B} 2$ and $\Delta \mathrm{L} 1$ correlated with $\Delta$ weight 
Table 3 Beta values from multiple regression analysis with the change of growth factors and growth markers as dependent variables and change of weight, ES, gluten amount, age and sex as independent variables. $\Delta$ Weight significantly contributed to the change of all growth factors and growth markers. $\triangle$ ES significantly contributed to $\triangle$ IGF-I SDS and $\triangle I$ GFBP-3 SDS. Gluten dose, age and sex had no significant influence upon the change of any of the growth factors or growth markers. $P$ values in parentheses. Total ALP and ALP isoforms are expressed in $\mu \mathrm{kat} / \mathrm{l}$, IGF-I, IGFBP-3 and ICTP in $\mu \mathrm{g} / \mathrm{l}$.

\begin{tabular}{|c|c|c|c|c|c|}
\hline $\begin{array}{l}\text { Growth factors and } \\
\text { markers }\end{array}$ & $\Delta$ Weight & $\begin{array}{l}\text { Severity of induced } \\
\text { histopathology }\end{array}$ & Gluten amount & Age & Sex \\
\hline$\Delta$ Total ALP & $0.47(0.0011)$ & $-0.15(0.30)$ & $-0.14(0.29)$ & $0.03(0.80)$ & $0.09(0.48)$ \\
\hline$\Delta$ Bone ALP & $0.38(0.011)$ & $-0.19(0.17)$ & $-0.14(0.32)$ & $0.04(0.78)$ & $0.08(0.50)$ \\
\hline$\Delta$ Bone ALP B/l & $0.15(0.36)$ & $-0.10(0.51)$ & $0.00(0.99)$ & $-0.17(0.25)$ & $0.08(0.62)$ \\
\hline$\Delta$ Bone ALP B1 & $0.31(0.04)$ & $-0.26(0.07)$ & $0.03(0.84)$ & $-0.15(0.28)$ & $0.12(0.40)$ \\
\hline$\Delta$ Bone ALP B2 & $0.39(0.012)$ & $-0.14(0.33)$ & $-0.18(0.20)$ & $0.10(0.45)$ & $0.09(0.55)$ \\
\hline$\Delta$ Liver ALP L1 & $0.39(0.009)$ & $0.06(0.60)$ & $-0.01(0.93)$ & $0.03(0.80)$ & $0.19(0.17)$ \\
\hline$\Delta$ Liver ALP L2 & $0.09(0.50)$ & $-0.21(0.15)$ & $-0.00(0.99)$ & $-0.07(0.82)$ & $-0.19(0.22)$ \\
\hline$\Delta$ Liver ALP L3 & $0.19(0.17)$ & $0.38(0.012)$ & $-0.27(0.055)$ & $0.06(0.70)$ & $0.05(0.74)$ \\
\hline$\Delta$ IGF-I SDS & $0.47(0.001)$ & $-0.36(0.021)$ & $-0.07(0.52)$ & $0.11(0.26)$ & $-0.16(0.18)$ \\
\hline$\Delta$ IGFBP-3 SDS & $0.29(0.031)$ & $-0.39(0.0042)$ & $-0.11(0.37)$ & $0.07(0.57)$ & $0.11(0.38)$ \\
\hline$\triangle \mathrm{ICTP}$ & $0.46(0.0026)$ & $-0.05(0.72)$ & $-0.17(0.18)$ & $0.03(0.18)$ & $0.06(0.62)$ \\
\hline
\end{tabular}

SDS. (Beta values were $0.31,0.39$ and 0.39 respectively, all with $P<0.05$.)

$\Delta$ ES correlations with $\Delta$ IGF-I and $\Delta$ IGFBP-3, $\Delta$ bone ALP isoforms and $\triangle I C T P$ were evaluated with registration of the partial correlation when adjusted for $\Delta$ weight SDS. There was a significant partial correlation of $\Delta \mathrm{ES}$ with $\Delta \mathrm{IGF}-\mathrm{I}, \Delta \mathrm{IGFBP}-3$ and bone ALP B2 but not with bone ALP, the isoforms B/I, B2 or $\Delta \mathrm{ICTP}$ (Table 4).

\section{Discussion}

The results demonstrate that decreased activities of all three bone ALP isoforms account for the major part of the previously noted decrease of total ALP during gluten challenge. The liver ALP L2 is reduced but the three liver ALP isoforms combined did not change. Closely correlated with the decrease of ALP and bone ALP isoforms was the decrease of the growth factors IGF-I and IGFBP-3 and of ICTP. We did not find any correlation between the reduction in growth factors or growth markers and increase of ALAT or ASAT. Thus, no indication was found that gluten-induced impaired

Table 4 Correlation impact of ES upon growth factors and growth markers when weight influence was adjusted for partial correlation coefficient.

\begin{tabular}{lll}
\hline & \multicolumn{2}{c}{ Partial correlation of ES } \\
\cline { 2 - 3 } & \multicolumn{1}{c}{$r_{\mathrm{s}}$} & $P$ \\
\hline$\Delta$ ALP & -0.21 & 0.13 \\
$\Delta$ Bone ALP & -0.23 & 0.11 \\
$\Delta$ Bone ALP B/I & -0.16 & 0.52 \\
$\Delta$ Bone ALP B1 & -0.30 & 0.04 \\
$\Delta$ Bone ALP B2 & -0.19 & 0.19 \\
$\Delta$ IGF-I SDS & -0.44 & 0.0011 \\
$\Delta$ IGFBP-3 SDS & -0.43 & 0.0013 \\
$\Delta$ ICTP & -0.16 & 0.53 \\
\hline
\end{tabular}

liver function was the cause of the reduction of growth factors and markers. Both weight loss and increase of mucosal inflammation (but not sex, age or gluten dose) were correlated with the decrease of IGF-I, IGFBP-3, ICTP, ALP and bone ALP isoforms. When influences of weight loss were adjusted for, partial correlation showed the degree of enteropathy to correlate with the decrease of IGF-I, IGFBP-3 and bone ALP isoform B1.

In this study, seven patients had a slight increase of ALP, but still within the normal range for age. Mora et al. (2) reported serum ALP activity above normal for age in 33\% of children with active coeliac disease. In adults, an increase in ALP has often been noted during gluten challenge. Bodé \& Gudmand-Hoyer (22) found an increase in ALP in as many as $27 \%$ of their patients and considered it a consequence of cholestasis or vitamin D deficiency. In our patients, there was no indication of cholestasis as gluten exposure caused liver ALP isoforms to decrease or remain unchanged (L1). The short time frame of the present study is a possible explanation for the lack of increase of ALP.

In prepubertal children from 1 year of age, the bone ALP contributes some $80 \%$ of total ALP (23), whereas in adults it accounts for about 50\%. Age-related reference values have been published for children 7-16 years of age (24). Serum concentration of bone ALP correlates with variations in growth velocity from infancy throughout childhood and puberty (25). The biological properties of the different bone ALP isoforms are not clear. However, the ALP isoform B1 is more abundant in cortical bone whereas the ALP isoform B2 is dominant in trabecular bone (7). During gluten challenge the small intestinal inflammation was correlated with the decrease of bone ALP isoform B1 and $\mathrm{B} 2$ but when weight reduction was adjusted for, only B1 showed partial correlation with $\Delta \mathrm{ES}$.

The impaired growth commonly noted in untreated coeliac disease is generally considered to be due to 
malabsorption and weight reduction, but whether the small intestinal inflammation contributes to the impaired linear growth is not established. Both conditions are associated with decreased levels of IGF-I and IGFBP-3. A low serum concentration of IGF-I in active coeliac disease compared with healthy controls or compared with patients on and off a gluten-containing diet has been found earlier $(8,9,26-29)$. Several possible explanations for the reduction of IGF-I and IGFBP-3 are to be considered.

The liver is considered the major supplier of circulating IGF-I (30). Despite increasing aminotransferases, there was no correlation between changes in ALAT or ASAT and changes in IGF-I or IGFBP-3 in this study. These results do not indicate impaired liver function to be the cause of IGF-I reduction.

The low IGF-I could be caused by malnutrition, since growth factors are known to be sensitive to nutrition. IGF-I is low in anorexia nervosa and it decreases during severe acute starvation. The reduction is considered not to be apparent until a certain threshold in weight loss of approximately $15 \%$ is reached (31). Interestingly, the average weight loss here was quite moderate, less than $1 \%$. Another cause of the decline in IGF-I could be inflammation. In inflammatory bowel disease, decrease of growth rate has been shown to correlate with disease activity (32), and somatomedin C, i.e. IGF-I levels were low in active disease (33). In this study the degree of inflammation was shown to correlate with $\Delta$ growth factors. When the influence of weight reduction was adjusted for, a significant partial correlation was evident between the gluten-induced mucosal inflammation and the changes in growth markers.

ICTP declined in parallel with the bone ALP isoforms and the reduction correlated with weight change but not with the small intestinal inflammation. While ALP is an indicator of bone formation, ICTP should be interpreted as a marker of type I collagen degradation. The positive correlation between ALP and ICTP was to be expected, since bone formation and resorption are usually highly proportional. Serum levels of ICTP correlate well with histomorphometric indices of bone resorption from iliac crest biopsies in disorders with high and low bone turnover $(34,35)$.

In this paper, we report the influence of gluten challenge in a standardised manner upon growth markers and growth factors and relate the results to both weight reduction and mucosal atrophy. Gluten challenge induces a significant reduction in bone ALP isoforms, IGF-I, IGFBP-3 and ICTP. The decrease of ALP, bone ALP isoforms $\mathrm{B} / \mathrm{I}$ and $\mathrm{B} 2$ and ICTP was correlated with weight reduction and eventually malnutrition is the cause of decreased bone turnover and reduced BMD. The decline in IGF-I and IGFBP-3 during gluten challenge can be separated from influences of weight reduction and can be related to the degree of small intestinal mucosa inflammation. This could be one explanation for the clinical finding of stunted growth in children with coeliac disease without clinical signs of malabsorption.

One possible mechanism behind a reduction of growth markers and growth factors, not studied here, is impaired GH secretion. There is a well-known relationship between $\mathrm{GH}$ secretion and levels of IGF-I and IGFBP-3 (36). Several publications report decreased GH secretion upon stimulation tests $(37,38)$, although other studies have failed to demonstrate such changes $(3,39)$. Decreased GH secretion, insufficient IGF-I synthesis by the liver, increased elimination or impaired peripheral tissue utilisation of one of these growth factors would result in diminished activity of the growth plate. In children all or part of the decrease of ALP could be secondary to diminished activity of the growth plate with subsequent reduction of linear growth. Further studies are needed to elucidate whether the decrease of IGF-I and IGFBP-3 is due to changes in $\mathrm{GH}$ or to a more direct influence on IGF-I and IGFBP-3.

\section{Acknowledgements}

We are grateful to Inga-Lena Hultman and Britt-Marie Käck for expert assistance, Lisbeth Larsson for skilful analyses and Nils-Gunnar Pehrson for statistical advice. We would also like to express our gratitude to all the children and parents who made this study possible. This work was supported by the Swedish Medical Research Council (grant 7509 and 7609), Göteborgs Läkaresällskap, Stiftelsen Samariten, Sven Jerring Fond, Pharmacia Corp. and Jönköpings Läns Vetenskapliga råd (grant 1472).

\section{References}

1 Ascher H, Holm K, Kristiansson B \& Mäki M. Different features of coeliac disease in two neighboring countries. Archives of Diseases in Childhood 199369 375-380.

2 Mora S, Weber G, Barera G, Bellini A, Pasolini D, Prinster C et al. Effect of gluten free diet on bone mineral content in growing patients with celiac disease. American Journal of Clinical Nutrition $199357224-228$.

3 Cacciari E, Salardi S, Lazzari R, Cicognani A, Collina A, Pirazzoli P et al. Short stature and celiac disease: a relationship to consider even in patients with no gastrointestinal tract symptoms. Journal of Pediatrics $1983 \mathbf{1 0 3}$ 708-711.

4 Jansson U, Kristiansson B, Albertsson-Wikland K, Larsson B \& Magnusson P. Biochemical growth markers during gluten challenge in children with coeliac disease. Seventh International Symposium on Coeliac Disease, Tampere, Finland, September 1996 (Abstract).

5 Magnusson P, Löfman O \& Larsson L. Determination of alkaline phosphatase isoenzymes in serum by high-performance liquid chromatography with post-column reaction detection. Journal of Chromatography $1992 \mathbf{5 7 6} 79-86$.

6 Magnusson P, Löfman O \& Larsson L. Methodological aspects on separation and reaction conditions of bone and liver alkaline phosphatase isoform analysis by high performance liquid chromatography. Analytical Biochemistry 1993211 156-163.

7 Magnusson P, Larsson L, Magnusson M, Davie MWJ \& Sharp CA. Isoforms of bone alkaline phosphatase: characterization and origin in human trabecular and cortical bone. Journal of Bone and Mineral Research 199914 1926-1933. 
8 Eichler I, Frisch H \& Granditsch G. Growth failure and insulinlike growth factor-I (IGF-I) in childhood celiac disease. Kliniche Wochenschrift 199169 825-829.

9 Weile B, Krasilnikoff PA, Giwercman A \& Skakkebaeck NE. Insulin-like growth factor-I in celiac disease. Journal of Pediatric Gastoenterology and Nutrition 199419 391-393.

10 Lindberg T, Berg NO, Borulf S \& Jacobson I. Liver damage in coeliac disease or other food intolerance in childhood. Lancet 19781 390-391.

11 Vajro P, Fontanella A, Mayer M, De Vincenzo A, Terracciano LM, D'Armiento $\mathrm{M}$ et al. Elevated serum transferase activity as an early manifestation of gluten sensitive enteropathy. Journal of Pediatrics 1993122 416-419.

12 Hildebrand H, Karlberg J \& Kristiansson B. Longitudinal growth in children and adolescents with inflammatory bowel disease. Journal of Pediatric Gastroenterology and Nutrition $1994 \mathbf{1 8}$ 165-173.

13 Saha M-T, Verronen P, Laippala P \& Lenko HL. Growth of prepubertal children with juvenile chronic arthritis. Acta Paediatrica 199988 724-728.

14 Fornari MC, Pedreira S, Niveloni S, Gonzales D, Diez RA, Vazquez $\mathrm{H}$ et al. Pre- and post-treatment serum levels of cytokines IL-1beta, IL-6, and IL-1 receptor antagonists in celiac disease. Are they related to the associated osteopenia?. American Journal of Gastroenterology 199893 413-418.

15 Ling SC. IGF-I. Letter to the editor. Journal of Pediatric Gastroenterology and Nutrition 199622337.

16 Meuwisse G. Diagnostic criteria in coeliac disease. Acta Paediatrica Scandinavica $1970 \mathbf{5 9} 461$.

17 Karlberg P, Taranger J, Engström I, Karlberg J, Landström T, Lichtenstein $\mathrm{H}$ et al Physical growth from birth to 16 years and longitudinal outcome of the study during the same period. Acta Paediatrica Scandinavica (Suppl) 1976258 7-76.

18 Blum WF \& Brier BH. Radioimmunoassays for IGFs and IGFBPs. Growth Regulation 19944 11-19.

19 Bouguszewski M, Jansson C, Rosberg S \& Albertsson-Wikland K. Changes in serum insulin-like growth factor I (IGF-I) and IGFbinding protein-3 levels during growth hormone treatment in prepubertal short children born small for gestational age. Journal of Clinical Endocrinology and Metabolism 199681 3902-3908.

20 Scandinavian Society for Clinical Chemistry and Clinical Physiology Committee on enzymes. Recommended methods for the determination of four enzymes in blood. Scandinavian Journal of Clinical and Laboratory Investigations 197433 291-306.

21 Risteli J. Elomaa I, Niemi S, Novamo A \& Risteli L. Radioimmunoassay for the pyridonoline cross-linked carboxy-terminal telopeptide of type I collagen: a new serum marker of bone collagen degradation. Clinical Chemistry 199339 635-640.

22 Bodé S \& Gudmand-Hoyer E. Symptoms and haematologic features in consecutive adult celiac patients. Scandinavian Journal of Gastroenterology 199631 54-60.

23 Van Hoof VO, Hoylaerts MF, Geryl H, Van Mullem M, Lepoutre LG $\&$ De Broe ME. Age and sex distribution of alkaline phosphates isoenzymes by agarose electrophoresis. Clinical Chemistry 1990 36 875-878.

24 Magnusson P, Häger A \& Larsson L. Serum osteocalcin and bone and liver alkaline phosphatase isoforms in healthy children and adolescents. Pediatric Research 199538 955-961.

25 Tobiume H, Kanzaki S, Hida S, Ono T, Moriwake T \& Yamauchi S. Serum bone alkaline phosphatase isoenzyme levels in normal children and children with growth hormone (GH) deficiency: a potential marker for bone formation and response to $\mathrm{GH}$ therapy. Journal of Clinical Endocrinology and Metabolism 1997 82 2056-2061.

26 Federico G, Favilli T, Cinquanta L, Ughi C \& Saggese G. Effect of celiac disease and gluten free diet on growth hormone binding protein, insulin like growth factor-I, and insulin like growth factor binding proteins. Hormonal Research 199748 108-114.

27 Locuratolo N, Pugliese G, Pricci F, Romeo G, Mariani P, DiazHorta $\mathrm{O}$ et al. The circulating insulin-like growth factor system in children with coeliac disease: an additional marker for disease activity. Diabetes/Metabolism Research Reviews 1999 $15254-260$.

28 Valdimarsson T, Arnqvist HJ, Toss G, Jarnerot G, Nystrom F \& Strom M. Low circulating insulin-like growth factor I in coeliac disease and its relation to bone mineral density. Scandinavian Journal of Gastroenterology 199934 904-908.

29 Hernandez M, Argente J, Navarro A, Caballo N, Barrios V, Hervas $\mathrm{F}$ et al. Growth in malnutrition related to gastrointestinal diseases: coeliac disease. Hormonal Research 199238 (Suppl 1) $79-84$.

30 Schwander JC, Hauri C, Zapf J \& Froesch ER. Synthesis and secretion of insulin-like growth factor and its binding protein by the perfused rat liver: dependence on growth hormone status. Endocrinology 198313 297-305.

31 Thissen JP, Ketelslegers JM \& Underwood LE. Nutritional regulation of the insulin-like growth factors. Endocrine Reviews $19941580-101$.

32 Hildebrand H, Aronson S \& Selvik G. Growth as a parameter of inflammation in Crohn's disease, using roentgen stereophotogrammetric analysis. Acta Paediatrica 199483 1070-1075.

33 Kirschner BS \& Sutton MM. Somatomedin C levels in growth impaired children and adolescents with chronic inflammatory bowel disease. Gastroenterology 198691 830-836.

34 Eriksen EF, Charles P, Melsen F, Mosekilde L, Risteli L \& Risteli J. Serum markers of type I collagen formation and degradation in metabolic bone disease: correlation with bone histomorphometry. Journal of Bone and Mineral Research 19938 127-132.

35 Garnero P, Shih WJ, Gineyts E, Karpf DB \& Delmas PD. Comparison of new biochemical markers of bone turnover in late postmenopausal osteoporotic women in response to alendronate treatment. Journal of Clinical Endocrinology and Metabolism 199479 1693-1700.

36 Blum WF, Albertsson-Wikland K, Rosberg S \& Ranke M. Serum levels of insulin-like growth factor I (IGF-I) and IGF binding protein-3 reflect spontaneous growth hormone secretion. Journal of Clinical Endocrinology and Metabolism 199376 1610-1616.

37 Day G, Evans K \& Wharton B. Abnormalities of insulin and growth hormone secretion in children with coeliac disease. Archives of Diseases in Childhood $1973 \mathbf{4 8} 41-46$.

38 Vanderschueren-Lodeweyckx M, Wolter R, Molla A, Eggermont E \& Eeckels R. Plasma growth hormone in coeliac disease. Helvetia Paediatrica Acta 197328 349-357.

39 Eichler I, Frisch H \& Granditsch G. Wachtumsstörung bei Kindern mit Zöliakie. Wien Klinisches Wochenschrift 198698 $366-367$.

Received 14 January 2000

Accepted 18 December 2000 